\title{
Organized crime as international law
}

\author{
Saeideh Yari ${ }^{1, *}$, Kobra Mamandi ${ }^{2}$ \\ ${ }^{1}$ M.A. Department of Criminology and criminal Law, Qom Branch, Islamic Azad University, Qom Science and Research Branch, Qom, \\ Iran \\ ${ }^{2}$ M.A. Law Criminal and Criminology, Islamic Azad University, Qom Branch, Iran
}

\section{Email address:}

Saeideh_yari@yahoo.com (S. Yari), Kobra Mamandi@yahoo.com (K. Mamandi)

\section{To cite this article:}

Saeideh Yari, Kobra Mamandi. Organized Crime as International Law. Humanities and Social Sciences. Vol. 2, No. 1, 2014, pp. 1-4. doi: 10.11648/j.hss.20140201.11

\begin{abstract}
Organized crime and law corruption are shaped by the lack of strength of the control mechanisms of the State and civil society. The results presented in the present article attest to the links between the growth of organized crime and that of corruption in the public sector in a large number of countries. The structure and organization of criminal justice services is an important building block in the quest for improved institutional performance. Virtually every national study commission and standard-setting group has offered recommendations on structure, usually as part of larger bodies of reform doctrine. Yet, structural proposals have rarely been sorted out, compared and analyzed across criminal justice components. This article outlines the difficulties of dealing adequately in legal terms with these phenomena and analyses the different approaches adopted so far at the national and international law level. The present article analyses the steps taken so far at the national and international level, against the background of the respective practical and theoretical challenges. Researchers believe that one of the most important aspects of effective management is to learn the science of organized crime.
\end{abstract}

Keywords: Criminal Justice, International Law, Institution, Organized Crime

\section{Introduction}

Numerous national and international instruments, in particular the United Nations Convention against Transnational Organized Crime, indicate that (transnational) organized crime' has become a legal concept whether this is the case or not is, however, of minor practical relevance. For the purposes of the present article it is important to understand why the definition of 'organized crime' is the object of continuing controversy and what this means for law-making and enforcement. Corruption and organized crime are much more than an isolated criminal phenomenon. Theoretical and applied researches have shown the interdependent links between the organized crime, criminal justice and legal domains. The present article explores those determining factors, relying upon several operational variables that reflect the prevailing institutional features of each country. Institutional linkages to organized crime and corruption in the public sector are first identified through a simple correlation analysis that does not necessarily imply causal effects. Factor analysis coupled with the application of multiple regression techniques narrows down the most important set of institutional linkages. The analysis was founded entirely on the development of corruption and organized crime indicators. Is the Criminal justice system doing its job to uphold its name? Many believe that Americas Criminal justice system is still experiencing problems with having the ability to decrease crime rates and giving citizens the feeling of safety in their homes and communities. Criminals, in the United States seem to get harsher punishment and much longer sentences than all other industrialized countries. It seems instead of preserving tranquility, the justice system allows social instability. Can it truly be called a system? The real question here is what is being done wrong in their policy and how will the criminal justice system resolve issues of violence, crime and safety. The prosecution function includes submission of criminal charges and supporting evidence to grand juries and preparation of cases for trial. Also known by such titles as district, state, or common wealth solicitor or attorney, in most states prosecutors are elected. In the federal system they are political appointees of the Justice Department. Whether an appointee or an elected official, a prosecutor often is a highly visible public figure, especially when 
involved with a celebrated criminal case. The prosecutor manages the office district attorney and in larger offices will appoint managerial deputy DAs to help with supervision and case management.

\section{How is "International Organized Crime"Defined?}

A definition of international organized crime is necessary to provide a common understanding of the issues addressed by the aforementioned programs and to set parameters for the development of policies and strategies on a national level. However, as previously discussed, international organized crime is a somewhat amorphous concept that does not easily lend itself to a concise definition. The problem stems not from the words international or crime, but from the word organized. Whether certain criminal activities are indeed organized thereby warranting prioritized law enforcement action has historically been a subject of great debate. The fact that IOC groups may exist in several forms further complicates the matter. While in practice, the definition may not fully illuminate the presence of organized crime in a particular case for prosecutors, it does serve as a helpful first step in making that determination.

\section{Controlling Organized Crime}

After the end of the Cold War, the topic of organized crime has become one of the new risks commonly mentioned. It is true that criminal activity was being transformed by globalization. Like any market activity, it adapts to new market constraints. They choose the markets that offer the best returns and most of opportunities. Or all types of behavior found in major economic players. Limited to this analysis seems insufficient. Criminal organization is a group, with a peculiar mode of organization: A. of at least three persons in America or abroad B. One of whose main purposes or main activities the facilitation or commission of one or more serious offenses that, if committed, would likely or provide a person who part - directly or indirectly, a material benefit, including financial. This definition does not include a group of persons that forms randomly for the immediate commission of one offense. There is another side to consider. The study of organized crime also reveals the attitude unlawful or illegal that has allowed the States themselves, including the most democratic. The concept is overloaded. It connotes the ten hypothetical attributes of organized crime:

1 - The power and the threat it poses to our democracy (which is implicit in the rest)

2- To have orderly operations

3 - The answer to a demand for illegal goods or services

4 - Professional criminals.

Most recently, the international dimension has enriched an already rich concept. It is now an open discussion on large transnational organized crime or "serious forms of transnational crime."[1] It sounds like the cry of alarm, suggesting that is fomenting a conspiracy to put the world in cross set. These contrasts with the subject of several criminologists show a marked skepticism, recalling that the proclamations of the Mafia based on hearsay or "studies" whose data are not disclosed. They refuse to believe in the periodontal police who say a lot but do not produce the documents. In the U.S., the argument that a vast criminal organization would control most of the activities of organized crime from a central management has been damaging several times. Organizational behavior in a criminal justice agency is the way in which employees and their superiors interact amongst themselves and with one another both positively and negatively. "Organizational behavior itself is the study of social conduct as it relates to the confines of a specific group; it is the study of how an individual or group interacts with one another and the dynamics of the personal relationships that evolve from" [2] The shifting paradigm trends describe by Schermerhorn, Hunt, and Osborn (2008) can be used to delve further into the understanding of the organizational behavior that exists in most criminal justice agencies. The archetypical performance falls into one of seven categories; commitment to ethical behavior, importance of human capital, demise of command-and-control, emphasis on team work, pervasive influence of information technology, respect for new workforce expectations, and changing careers. From these trends both positive and negative characteristics of criminal justice agencies can be identified. "Commitment to ethical behavior: Highly publicized scandals involving unethical and illegal business practices prompt concerns for ethical behavior in the workplace; there is growing intolerance for breaches of public faith by organizations and those who run them" (3). In criminal justice agencies ethical violations often are handled with little fan fair. Any level of impropriety introduced in the prying public eye can have innumerous repercussions. The loss of public support and trust can be a huge problem, but it affects the internal structure too. Depending on how fairly and swiftly the situation is handled determines whether or not those in charge gain or lose respect. Judgments will be passed on how the situation was controlled, and how it should have been in situation. Are prisons a way of reducing crime rates? Paul Leighton, a Professor in the Dept of Sociology, Anthropology \& Criminology at Eastern Michigan University believes prisons are part of a comprehensive crime-fighting regime, but they are only a small component. Excessive reliance on prisons brings little additional safety. Imprisonment occurs long after the crime has been committed and mostly incapacitates an offender from committing more crimes against people on the outside. It does not prevent crime and inmates frequently come out of prison worse than they went in, with few additional skills or pro-social behavior. Overall, high rates of incarceration have little or no correlation to rates of crime. States with high rates of incarceration may or may not have high rates of crime. States with low rates of crime may or may not have 
high rates of incarceration. Similarly, states that embark on massive prison construction programs may or may not show declines in crime.

The number of people locked up has quadrupled since 1980. There were over 2 million people in prisons and jails nationwide. An additional 4.7 million people are on probation or parole to measure the prevalence of organized crime, the study used an index that combined objective factors linked with complex crimes. The development of an international index of organized crime obviously had to start, from a universally agreed upon definition. During the 1990s, law enforcement agencies in Europe developed a number of operational definitions of the term organized criminal group. Those definitions agree on the following crucial elements: such a group is structured, has some permanence, commits serious crimes for profit, uses violence, corrupts officials, launders criminal proceeds and reinvests in the licit economy. The United Nations Convention against Transnational Organized Crime defines an organized criminal group as a structured group, committing serious crimes for profit. That very broad definition was favored over the listing of the most common types of organized crime such as trafficking in drugs, arms, persons, stolen cars or protected species and terrorism. The Convention thus focuses on the same types of group as are targeted by law enforcement agencies using the Falcone checklist, which was later incorporated into the so-called Falcone framework. This is evident from the three protocols supplementary to the Convention, dealing with trafficking in persons, smuggling of migrants and trafficking in firearms, as well as from provisions in the Convention dealing with such secondary characteristics of organized crime as the use of corruption, violence, money-laundering and reinvestment in the licit economy. For the purposes of calculating the organized crime index used here, the extent of organized crime in a country was assessed on the basis of indicators of the various defining elements contained both in operational investigations conducted by law enforcement agencies (e.g. the Falcone checklist) and in the Organized Crime Convention and its protocols. It was also concluded that official data on police records of criminal activities offered little reliable information on the extent of organized crime activity in a country and that other sources would have to be found or developed. "One potentially relevant source is the World Economic Forum's survey of business aimed at measuring the costs imposed by organized crime on firms" [4], which provides an estimate of the extent of victimization of businesses by organized crime. The country ranking based on the World Economic Forum's index was subsequently correlated with indices for corruption and violence (homicide). "The three indices were found to be highly correlated across a group of 70 countries and, as a result, a composite index of non-conventional crime was constructed" [5]. This composite index of organized crime is used in the analysis below. It should be noted that although the composite index has proved to be robust and not much affected by the inclusion or exclusion of individual indicators, efforts are nevertheless ongoing to add further statistical indicators. The purpose of the study was to derive policy recommendations addressing institutional reform through a process of identifying best practices across the globe.

\section{Criminal Justice System}

The criminal justice system of a country is a key factor in any analysis of how effective the State is in responding to serious crimes, in particular organized crime. What surfaced from initial analyses here was that the number of personnel employed in police and prosecution services was positively correlated with levels of organized crime. The immediate explanation is that, in countries with high crime rates, the first response of the State is to increase the number of police personnel, therefore the higher the crime rate, the more personnel the country will need to come to terms with the problem. More generally, that trend is also confirmed, if the financial resources invested in a criminal justice system are considered. In that analytical context, the size of the payroll and the money spent on criminal justice is positively related to the level of organized crime. The study presented here also considered measurements of the effectiveness of criminal justice systems. It is noteworthy that an international index of total recorded crimes per capita is related inversely to the level of organized crime. In countries with lower levels of organized crime, higher percentages of drug arrests are recorded. In countries with high levels of organized crime, the criminal justice system may not be able to deal adequately with crimes committed and official statistics may thus not reflect the actual nature and scale of crimes perpetrated. On the other hand, when a criminal justice system works properly, in terms, for example, of more arrests and convictions for drug trafficking, that institutional effectiveness helps to control organized crime better. In many countries with less than effective law enforcement institutions, victims lack confidence in state institutions and so citizens rarely report crimes or request police intervention. In such environments, citizens often find support in illegal organizations, such as mafia-type groups, to deal with minor crimes. Ironically, then, low levels of recorded crimes and drug arrests in a country may point to low effectiveness of the police and a relatively high prevalence of organized crime. "In order to come to terms with the above constraints, the present study proposed a more direct measure of effectiveness of criminal justice, consisting of computing the ratio of victimization by common crime derived from the International Crime Victim Survey divided by the number of convictions per capita" [6] A smaller ratio can be seen as a measure of effectiveness of criminal justice since it reflects higher risks of punishment for offenders per crime committed. After correlating the measure of such effectiveness with the organized crime index, a clear association emerged between the two variables that is, the level of organized crime is lower in countries where the conviction rates per crimes committee dare higher. 
In other words, the presumed deterrent effect of functioning criminal justice systems with regard to organized crime is clearly demonstrated in the present analysis.

\section{Conclusion}

The results of the analyses reported here have shown that levels of organized crime and of corruption in the public sector are determined first and foremost by the quality of core public state institutions, such as the police, prosecution and the courts. That relationship seems to hold for countries at all levels of development. It is also clear that the institutional forces at work in introducing improvements in the legal fight against corruption and organized crime must be held accountable. These are the conditions that foster the "right" institutional environment within which criminal justice can be offered in an unbiased and transparent fashion. Independently from these institutional determinants, high levels of organized crime and corruption are linked to low levels of human development. This result points to the vicious circle of poverty exploited and compounded by organized crime and grand corruption.

\section{References}

[1] Jay S. Albanese, Translational Crime and the 21st. Century. Oxford University Press, 2011.

[2] Robinson, Brian. Organizational Behavior in Criminal Justice. January 10, 2011.

[3] John R. Schermerhorn Jr., James G. Hunt, Richard N. Osborn. Organizational Behavior, p.14, 2008.

[4] World Economic Forum, "Organized crime imposes cost on businesses", The Global Competitiveness Report 2002-2003. New York: Oxford University Press, 2003.

[5] Jan van Dijk and Sami Nevala. "Interco relations of crime: results of an analysis of the correlations between indices of different types of conventional and non-conventional crime", Crime Victimization in Comparative Perspective, pp. 182-193, 2002.

[6] Anna Alvazzi del Frate. "The voice of victims of crime: estimating the true level of conventional crime", Forum on Crime and Society, vol. 3, Nos. 1-2, 2003 